radiologically before removal, as is the relationship of the teeth to the length of string. The position of any blood-staining on the string is taken as an indication of the site of bleeding.

Laparotomy.-This is occasionally indicated when patients go on bleeding for no obvious cause, but the operation is seldom rewarding, particularly if carried out during an interval when the bleeding has stopped. If a definitive diagnosis has not been reached it is probably better to keep the patient under observation and be prepared to re- $x$-ray at intervals if it is suspected that a neoplasm may in fact be present. In relation to such a policy it is reassuring that of 68 patients diagnosed originally as having iron deficiency anaemia with unexplained occult bleeding 51 remained unexplained." The majority were in good health 2 to 21 years later apart from relapse of the anaemia in some cases. Of the other 17,12 were thought to have been bleeding because of aspirin ingestion, two had bleeding piles, one had been found to have a gastric ulcer, one a possible carcinoma of the rectum, and one a definite carcinoma of the colon. This last case is probably the only one in which laparotomy might have been helpful at the time of the original admission, but even then with completely negative $x$-ray findings a small tumour might have been missed, since the surgeon had no guidance on where to look for it.

\section{Conclusions}

Persistent and occult blood loss from the gastrointestinal tract is not necessarily a sinister symptom. It is now recognized that in a high proportion of cases the cause is ingestion of drugs of the salicylate group. A careful history and clinical examination will go far towards detecting many of the causes of persistent blood loss. Special investigations such as barium studies, gastroscopy, and sigmoidoscopy are mainly needed to look for peptic ulcers, hiatus hernia, and neoplasms. Laparotomy should not be undertaken lightly as a diagnostic procedure:

\section{REFERENCES}

1 Bedford, P. D., and Wollner, L., Lancet, 1958, 1, 1144

Beveridge, B. R., Bannerman, R. M., Evanson, J. M., and Witts, L. J., Quart. 7. Med., 1965, 34, 145.

- Halt, P. R., 7. Lab. clin. Med., 1960, 56, 717

- Bannerman, R. M., Beveridge, B. R., and Witts, L. J., Brit. med. 3. $1964,1,1417$.

\title{
MEDICINE IN THE TROPICS
}

\section{Hypertension in the Tropics}

\author{
K. L. STUART,* M.D., F.R.C.P., F.R.C.P.ED., D.T.M.\&H
}

There is good evidence that patterns of blood pressure and the prevalence of hypertension vary considerably from country to country. Within each country there may also be wide variations from region to region and from group to group. Probably the widest variations are found in the reports from the African continent. Donnison ${ }^{1}$ had encountered no case of raised blood pressure in a period of two years in a native reserve hospital in Kenya : and Williams ${ }^{2}$ found essential hypertension uncommon in Africans in Uganda. On the other hand, Shaper ${ }^{3}$ showed that hypertension was quite common in hospital populations in East Africa and accounted for the largest proportion of cardiovascular admissions.

Moser and his colleagues 4 showed that in Liberia mean blood pressure levels in most ages and both sexes are lower than the mean levels noted in negroes in the West Indies, the United States, and southern and central Africa; whereas a high frequency for elevated blood pressure has been found in the negro in the Belgian Congo. ${ }^{5}$ Reports from South Africa also indicate that hypertension is not uncommon among the Bantu and other negro populations in Cape Town and that the severity of the hypertension is more pronounced in the negro than in whites living in this area. ${ }^{6}$

Prevalence rates for hypertension have also been shown to be higher in negro groups in the West Indies ${ }^{7-9}$ and in the United States ${ }^{10}$ than in comparable white populations. The ancestors of most American and West Indian negroes came from West Africa in the second half of the eighteenth century. Although data concerning the blood pressure levels in the general population of West Africa are relatively sparse, available data from this area indicate that blood pressure levels and their relationship to age and sex differ in no respect from values obtained in white races. ${ }^{11}$

The demonstration that many communities in the troptcs and sub-tropics show relationships of blood pressure to age

- Professor of Medicine, University of the West Indies, Jamaica. and sex that are comparable to those found in Western countries is of much interest. Of possibly greater interest has been the identification of communities where mean blood pressure levels are low and show no rise with age-in certain nomadic pastoral tribes in Kenya, ${ }^{3}$ in Pacific island populations, ${ }^{12}{ }^{13}$ in low income groups in New Delhi, ${ }^{14}$ among the Cuna Indians, ${ }^{15}$ and in many other areas. In some com-. munities-the Gilbertese and other Micronesian populations, for example, and also in South Korea ${ }^{13}$-blood pressures in women have been found to remain below those of men in later years. No reasons for these differences are at present available. They are nevertheless of great importance; and no theory about the aetiology of hypertension which fails to explain them can be entirely adequate.

\section{Aetiology}

In tropical areas where elevated blood pressure levels have been reported varying aetiologies have been advanced. In Georgia a possible role for syphilis has been discussed. ${ }^{10}$ In East Africa ${ }^{3}$ and in Panama ${ }^{16}$ pyelonephritis and glomerulonephritis are considered of major importance. In the Bahamas, a high salt intake has been thought a possibly important factor. ${ }^{4}$ In Jamaica, though significant bacteriuria was found in $15 \%$ of females in a rural area with diastolic pressures exceeding $110 \mathrm{~mm} . \mathrm{Hg}$ as compared with $0.5 \%$ of males, it was considered that urinary tract infection might contribute to, but not entirely explain, the high levels of blood pressure found in these surveys. ${ }^{8}$ However, the high prevalence of pyelonephritis found on post-mortem examination of subjects with hypertension in Jamaica has suggested that the role of urinary tract infection in the genesis of hypertension may be far greater than has been suggested by the survey findings. ${ }^{17}$

In Jamaica it has been possible to relate blood pressure levels to age, sex, heredity, parity, and body-build as in 
comparable Welsh surveys. ${ }^{8}$ An unexplained relationship between elevated blood pressure levels and uterine fibroids in women has also been demonstrated in Jamaica, ${ }^{18}$ as in other areas. ${ }^{19}$

It is of interest that in St. Kitts, in spite of high prevalence rates for hypertension, evidence of coronary atheroma was infrequent. ${ }^{20}$ It is suggested that, as among negro men in the United States, ${ }^{21}$ the influence of hypertension on coronary atherogenesis may be counteracted by other influences such as relatively low serum cholesterol levels and, possibly, heavy muscular work.

The diagnosis of primary or essential hypertension can be made only after excluding conditions known to produce elevations of blood pressure. Renal causes of hypertension such as glomerulonephritis, chronic pyelonephritis, polycystic kidneys, and various forms of unilateral renal disease occur with sufficient frequency in tropical areas to make their exclusion necessary in the evaluation of all patients with elevated blood pressure levels. In general, the younger the patient the more careful should be the search for an underlying cause.

\section{Special Considerations}

Because of social and economic circumstances the management of hypertension in most tropical countries presents a more difficult problem than it does elsewhere. In planning a treatment programme for hypertension in the tropics the following factors are of ten important :

(1) The acute shortage of hospital beds makes it necessary for a greater proportion of patients to be treated entirely on an outpatient basis than in "Western" communities. It commonly happens that only those patients with advanced and often terminal hypertensive disease can obtain admission to hospital-the group for which treatment achieves little.

(2) The successful management of a disorder like hypertension requires the co-operation of an intelligent patient. Many patients attending outpatient clinics or general practitioners in the tropics come from socio-economic and educational groups from which intelligent co-operation can be obtained only infrequently.

(3) In all countries the high incidence of troublesome sideeffects tends to reduce the proportion of patients who will continue to accept adequate treatment. In areas where additional factors such as heavy manual labour and exposure to heat tend to increase the side-effects of hypotensive agents, patients are even more likely to default from treatment.

Treatment in the tropics, therefore, should be of the simplest possible design and specially tailored for each area, and education of the patient about his disorder should be an essential part of treatment. Furthermore, a minimum of sideeffects from any drug may be of crucial importance for its successful long-term use.

Programmes should be designed in such a way that a subsequent analysis of their effectiveness can be done. Until some evaluation of treatment is possible, particularly in the circumstances that obtain in the tropics, the indications for, and the methods and values of, treatment will continue to be vague and uncertain, and the enthusiasm of those responsible for it will be correspondingly low.

\section{When to Treat}

The decision to treat or not to treat a given patient in the tropics, as elsewhere, may depend on many factors other than blood pressure levels-the availability of medical personnel, the socio-economic, educational, and temperamental make-up of individuals and communities, and the local availability of drugs. There are therefore no hard and fast indications that can apply equally in all areas. We are convinced, however, that once treatment is considered necessary the aim should be to maintain blood pressure levels as near as possible to an arbitrary norm of $120 / 80$, except where there are specific contraindications; and that no treatment at all is far preferable to inadequate or sporadic attempts at blood pressure control.

Attendance at special clinics organized for the purpose is, where feasible, the most effective means of ensuring satisfactory blood pressure control in areas where large numbers require treatment. These clinics need not be elaborate. Their main function is to co-ordinate and streamline existing facilities into the most efficient and economical operational design.

It has been emphasized that one of the most important functions of a treatment programme for hypertension in the tropics is educational. Another is to obtain the trust and confidence of the patients under treatment. Both of these objectives are more readily achieved in clinics and health centres organized specifically for this purpose.

\section{Treatment}

The imposition of unreasonable restrictions should be avoided. Restriction of salt potentiates the action of hypotensive drugs and it certainly facilitates the management of cardiac failure in those who require digitalis and diuretics. Very severe restriction of salt, however, may be dangerous, particularly in the humid tropics. Limitation of added salt at table and in cooking is probably all that is required in these days of potent oral diuretics.

In most areas of the tropics it is advantageous to administer drugs in the simplest schedules consistent with effectiveness. We find it an advantage, for instance, to give medication in such a way that all drugs can be taken once or twice per day and at the same time each day. Differing schedules for differing drugs can be confusing and often dangerous.

Of the wide range of hypertensive drugs that are currently available the oral diuretics probably have the greatest overall usefulness. A simple oral diuretic like hydrochlorothiazide is usually administered in doses of $50 \mathrm{mg}$. twice or three times daily. Potassium supplements can usually be given by advising the use of potassium-containing fluids like coconut water, orange juice, or other fruit juices. Where necessary, potassium chloride may be prescribed in doses of $15 \mathrm{gr}$. (1 mg.) three times daily.

Where a diuretic alone is not adequate for blood pressure control, we combine it with an appropriate hypotensive agent. A drug like methyldopa has the advantage that it tends to produce less side-effects than guanethidine. However, it is not always as effective in reducing the more marked elevations of blood pressure.

Although the treatment of the pregnancy toxaemias in the tropics does not differ from their treatment in Western countries, they do appear to occur more commonly in tropical areas, and particularly in areas where subnutrition and malnutrition are common. Oral diuretics, bed rest, and sedation constitute, as elsewhere, the most reasonable approach to their treatment.

Details of drugs and dosages suitable for the treatment of individual cases of hypertension in the tropics do not differ in any significant degree from those recommended in temperate areas, and can be found in standard textbooks of medicine. No attempt is made, therefore, to set these out in any further detail. More important is to emphasize that good success can be obtained when medical personnel are enthusiastic and imaginative and willing to adapt and vary their methods of 
treatment to fit in with local social, economic, or physical circumstances.

In the West Indies and in many other tropical areas hypertension and its complications are common causes of morbidity and mortality as they are in most Western countries. For reasons detailed above there are commonly also more obstacles to effective treatment in the tropics than elsewhere. The problem that hypertension presents in many tropical countries is correspondingly increased. In the West Indiesand this is probably true for many other parts of the tropicsit remains one of the most important and unresolved challenges to medicine.

REFERENCES

Donnison, C. P., Lancet, 1929, 1, 6.

Williams, A. W., E. Afr. med. $\%$. 1941, 18, 109

Shapes. A. G., International Working Symposium on the Epidemiology of Hypertension, Chicago, 1964.

- Moser, M., Harris, Ml., Pugatch, D., Ferber, A., and Gordon, B., Amer. 7. Cardiol., 1962, 10, 424.

- Van Dooren, F. R., and Rogowsky, M., 1958, quoted by Moser et al., ibid., $1962,10,424$

- Schrire. V., Amer. Heart F., 1958, 56, 742.

Schneckloth, R. E., Stuart, K. L., and Moore, F. E., ibid., 1962, 63,

- Miall, w. E., Kass, E. H., Ling, J., and Stuart, K. L., Brit. med. f., 1962, 2, 497

- Moser, M., Morgan, R., Hale, M., Hoobler, S. W., Remington, R. Dodge, H. J., and Macaulay, A. I., Amer. Y. Cardiol., 1959, 6, 727 .

10 Comstock, G. W., Amer. F. Hyg., 1957, 65, 272.
11 Abrahams, D. G., Alele, C. A., and Barnard, B. G., W. Afr. med. F., $1960,9,45$.

12 Maddocks, I., Lancet, 1961, 2, 396

18 Lovell, R. R., H., International Working Symposium on the Epidemio. logy of Hyperiension, Chicago, 1964.

14 Padmavi, S., and Gupta, S., Circulation, 1959, 19, 395.

15 Kean, B. H., Amer. 7. trop. Med., 1944, 24, 341.

10 Taylor, C. E., Amer. I. Path., 1945, 21, 1031 .

17 Taylor, C. E., Amer. F. Path., 1945, 21, 1031

18 Lovell, H. G., Mrit. Med. W., 1960, 1, 1173. 7., 1966, 15, 45.

10 Everett, H. S., and Scott, R. B., Amer. F. Obstet. Gynec., 1942, 44, 1010

${ }^{20}$ Stuart, K. L., Schneckloth, R. E., Lewis, L. A., Moore, F. E., and Corcoran, A. C., Brit. med. F., 1962, 2, 1283 .

"Berkson, D. M., Stamler, J., Lindberg, H. A., Miller, W., Mathies, H., Laskey, H., and Hall, Y., Ann. N.Y. Acad. Sci. 1960, 84, 835 .

\section{B.M.J. Publications}

The following are available from the Publishing Manager, B.M.A. House, Tavistock Square, London W.C.1. The prices include postage.

Porphyria-a Royal Malady ... $\quad \ldots \quad$ Price 13s. 6d.

Is There an Alternative? ... ... Price 7s. 6d.

Treatment of Common Skin Diseases Price 10s.

Obstetrics in General Practice _.. Price 32s. 6d.

Child Care ... ... ... ... Price 32s. 6d.

Charles Hastings and Worcester ... Price 3s. 6d.

\title{
ANY QUESTIONS?
}

\begin{abstract}
We publish below a selection of questions and answers of general interest.
\end{abstract}

\section{Termination of Pregnancy}

Q.-What is the best method of terminating a pregnancy in the first three months of pregnancy? Are hormone preparations effective as abortifacients, and, if so, which?

A.- There is mounting evidence from many sources that vacuum aspiration of the uterine contents is the safest and most efficient method of terminating pregnancy in the first three months. ${ }^{12}$ There is no convincing evidence that any hormone preparation is effective as an abortifacient.

\section{REFERENCES}

1 Dvořák, Z., Trnka, V., and Vašícek, R., Lancet,

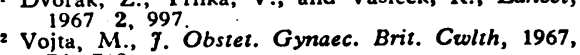
74, 768 .

\section{Continuing Barbiturate Medication}

Q.-A woman has taken cyclobarbitone $400 \mathrm{mg}$. per night for the past two years to induce sleep. What are the dangers of continuing this medication?

A.-Long-continued medication of the kind described may induce a state of dependence. Barbiturate-type dependence is all too cornmon.' It is usually induced by long-continued administration of any barbiturate, usually but not necessarily in excess of the therapeutic dose. The dosage referred to in the question is not in excess but it is at the upper limit. Cyclobarbitone is speedy in onset, and a dose of $200 \mathrm{mg}$. might be sufficient to induce sleep in this patient while avoiding the hazard of addiction.

$$
\begin{aligned}
& \text { REFBRENCB } \\
& \text { Eddy, N. N. B., Halbach, H.j Isbell, H., and } \\
& \text { Seevers, M. H., Bull. Wid Hith Org., 1965, } \\
& \text { 32, 721. }
\end{aligned}
$$

\section{Oil of Bergamot on the Hair}

Q.-Is there any harm in using undiluted eau-de-Cologne as a daily hairdressing?

A.-Eau-de-Cologne is an alcoholic solution of perfumes of plant origin. These almost invariably include oil of bergamot. Bergamot and some other essential oils contain a furocoumarin. In most circumstances undiluted eau-de-Cologne could safely be used as a hairdressing, but it must involve a slight risk of inducing disfiguring pigmentation under certain conditions.

When a perfume containing bergamot oil is applied to the skin shortly before exposure to sunlight intense and rather persistent pigmentation may be induced through the photodynamic action of the furocoumarin. This is not merely a theoretical hazard. Every dermatologist sees a few such cases each year even in Britain, and in sunnier climates eau-de-Cologne pigmentation is relatively frequent. Not all individuals are equally susceptible, and the variation in susceptibility seems to depend on variation in the skin's capacity to absorb the furocoumarin. This is certainly enhanced by hot and humid conditions, and there is some evidence that it is greater in middle-age than in youth.

It is therefore safer to substitute for eaude-Cologne a simple spirit lotion without perfume.

\section{Notes and Comments}

Booster Doses of Rabies Vaccine.-Dr. H. D. WilsoN (County Medical Officer, Haddington, East Lothian) writes : I was interested to read your expert's reply to this question ("Any Questions?" 9 December, p. 609). In this county there is a quarantine kennels, and during the last two years there have been two rabies "scares" among animals in quarantine from abroad. Fortunately both turned out to be negative, but, since it takes three weeks to have one's fears confirmed or refured, it was necessary to give rabies vaccine to the kennel staff who had been in contact with the suspected animal. They were given a full course of 14 injections of duck embryo vaccine.

It seemed desirable to maintain by appropriate boosting doses the immunity thus achieved, but I was advised that in the absence of serum antibody esumations boosting doses would be needed at six-monthly intervals. Since the kennel staff were reluctant to submit to this, the question of boosting doses was allowed to go by default. This seemed rather regrettable, and I wonder what your expert would advise about boosting doses in such cases.

OUR EXPERT replies: In the instance quoted booster doses would be considered unnecessary. In any event, however, booster doses when indicated need be given only on the 10th and 20th days after the completion of a full course of vaccine. Neither serum estimations nor sixmonthly booster doses are mandatory. 